Supplementary information: S1

Quantitative Assessment of Intrinsic Carbonic Anhydrase Activity and the Capacity for Bicarbonate Oxidation in

\title{
Photosystem II
}

Warwick Hillier ${ }^{\ddagger}$, Iain McConnell ${ }^{\ddagger}$, Murray R. Badger ${ }^{\ddagger}$, Alain Boussac ${ }^{\S}$, Vyacheslav V. Klimov ${ }^{\|}$, G. $^{\prime}$

Charles Dismukes $\stackrel{\perp}{\text {, and Tom Wydrzynski }} i^{*}$ 


\section{Supplementary information: S1}

The calculation of errors for the experimental fitted data was discussed in the methods section. The fitted parameters after least squares fitting were then used to calculate the $\left[{ }^{18} \mathrm{O}\right]$ leakage from $50 \mathrm{mM}$ $\mathrm{HC}^{18} \mathrm{O}_{3}{ }^{-} \rightarrow \mathrm{H}_{2}{ }^{18} \mathrm{O}$ using Equation 5. The uncertainty of the final ${ }^{18} \mathrm{O}$ concentration was based on examination of the covariance of $k_{1}$ and $k_{2}$ rate constants and the matrix is shown below with $k_{1} \pm 1 \mathrm{SD}$ and $k_{2} \pm 1 \mathrm{SD}$ and the resultant concentration of $\mathrm{H}_{2}{ }^{18} \mathrm{O}$. The maximum error coincided as a diagonal element and was used as the final measure of uncertainty. i.e.

\begin{tabular}{|c|c|c|c|}
\hline & $k_{1}-\mathrm{SD}$ & $K_{1}$ & $k_{1}+\mathrm{SD}$ \\
\hline$k_{2}-\mathrm{SD}$ & 9.5350 & 9.5365 & 9.5379 \\
\hline$k_{2}$ & 9.6169 & 9.6184 & 9.6198 \\
\hline$k_{2}+\mathrm{SD}$ & 9.6988 & 9.7002 & 9.7017 \\
\hline
\end{tabular}

The differences compared to the solution $k_{1}, k_{2}$ are:

\begin{tabular}{|cccc}
\hline \multicolumn{1}{|c}{} & \multicolumn{1}{c}{$\boldsymbol{k}_{1}-\mathbf{S D}$} & $\boldsymbol{K}_{1}$ & $\boldsymbol{k}_{1}+\mathbf{S D}$ \\
\cline { 2 - 2 } $\boldsymbol{k}_{2}-\mathbf{S D}$ & 0.0834 & 0.0819 & 0.0805 \\
$\boldsymbol{k}_{2}$ & 0.0015 & 0 & 0.0014 \\
$\boldsymbol{k}_{2}+\mathbf{S D}$ & 0.0804 & 0.0819 & 0.0833 \\
\hline
\end{tabular}

Thus the ${ }^{18} \mathrm{O}$ leakage for the spinach sample was estimated as $9.6184 \pm 0.0834$. The additional parameters for the fitting such as $k_{\text {leak }}$ were ignored as the changes were much smaller than those relating to $k_{1}$ and $k_{2}$. The $\left[\mathrm{HCO}_{3}{ }^{-}\right]$concentration term for the fitting was fixed $(50 \mathrm{mM})$, and the $k_{\text {transport }}$ did not enter into the derivation of the internal $\mathrm{CO}_{2} \leftrightarrow \mathrm{HCO}_{3}^{-}$equilibrium. 